\title{
COMPARISON OF MALES AND FEMALES WITH ANKYLOSING SPONDYLITIS: A CROSS SECTIONAL STUDY IN A BRAZILIAN SAMPLE
}

\author{
Naiana Diaz ${ }^{1, \star}$, Pedro Henrique Parisenti Badalotti ${ }^{1}$, Rafaela Angeli Weiler ${ }^{1}$, Juliana Simion ${ }^{1}$, Ana Paula Beckhauser ${ }^{1}$, Thelma \\ Larocca Skare $^{1}$, Nelzi Ferreira de Queiroz Junior ${ }^{1}$
}

1.Instituto Presbiteriano Mackenzie, Curitiba (PR), Brazil.

*Corresponding author: naiana.diaz@gmail.com

\section{BACKGROUND}

Ankylosing spondylitis (AS) is a chronic rheumatic disease historically considered to be more common in men. However, recent data has suggested that females may have a higher rate of this disease than previously though. The diagnosis may be delayed in females because women may display a clinical profile different from men. The aim of this work was to study comparatively males and females with AS in a Brazilian sample.

\section{METHODS}

Cross-sectional study including AS patients that were studied for clinical and epidemiological data. Disease activity was measured by Bath ankylosing spondylitis disease activity index (BASDAI), ankylosing spondylitis disease activity score-erythrocyte sedimentation rate (ASDAS-ESR), and ASDAS-CRP (C reactive protein). The Maastricht ankylosing spondylitis enthesitis score (MASES) was used to estimate enthesitis; function was assessed by Bath ankylosing spondylitis functional index (BASFI) and the ankylosing spondylitis quality of life (ASQoL) questionnaire was used to evaluate quality of life.

\section{RESULTS}

Ninety AS patients were included ( 36 females and 54 males) in a male/female proportion of 1.5 to 1 . Males and females have the same age at first symptoms but females had diagnosis done later $(p=0.04)$. Females had more enthesitis $(p=0.03)$ and males had more HLA-B27 ( $p=0.001)$ and a tendency to have more inflammatory low back pain $(p=0.06)$. The scores ASDAS-ESR, ASDASCRP and MASES were higher in females than males (with $p=0.01 ; 0.03$ and 0.003 respectively) but BASFI and ASQoL showed no differences $(p=n s)$. The results of HLA B27 were available in 46 patients. Comparing male and females with positive HLA B27, the results were similar to those obtained in the comparison with the whole sample.

\section{CONCLUSION}

Compared to men, women had a later diagnosis of AS. They presented more enthesitis and inflammatory activity and less HLAB27. The presence of positive HLA-B27 did not attenuate these differences.

\section{KEYWORDS}

Ankylosing spondylitis, Spondyloarthritis, Females. 